\title{
Factors Affecting Microbial Load and Profile of Potential Pathogens and Food Spoilage Bacteria from Household Kitchen Tables
}

\author{
Susheela Biranjia-Hurdoyal and Melissa Cathleen Latouche \\ Department of Health Sciences, University of Mauritius, 80837 Reduit, Mauritius \\ Correspondence should be addressed to Susheela Biranjia-Hurdoyal; s.biranjia@uom.ac.mu
}

Received 5 February 2016; Revised 24 May 2016; Accepted 31 May 2016

Academic Editor: Marianna Ofner

Copyright (c) 2016 S. Biranjia-Hurdoyal and M. C. Latouche. This is an open access article distributed under the Creative Commons Attribution License, which permits unrestricted use, distribution, and reproduction in any medium, provided the original work is properly cited.

\begin{abstract}
The aim was to study the bacterial load and isolate potential pathogens and food spoilage bacteria from kitchen tables, including preparation tables and dining tables. Methods. A total of 53 households gave their consent for participation. The samples were collected by swabbing over an area of $5 \mathrm{~cm}$ by $5 \mathrm{~cm}$ of the tables and processed for bacterial count which was read as colony forming units (CFU), followed by isolation and identification of potential pathogens and food spoilage bacteria. Result. Knowledge about hygiene was not always put into practice. Coliforms, Enterococcus spp., Pseudomonas spp., Proteus spp., and S. aureus were detected from both dining and preparation tables. The mean CFU and presence of potential pathogens were significantly affected by the hygienic practices of the main food handler of the house, materials of kitchen tables, use of plastic covers, time of sample collection, use of multipurpose sponges/towels for cleaning, and the use of preparation tables as chopping boards $(p<0.05)$. Conclusion. Kitchen tables could be very important source of potential pathogens and food spoilage bacteria causing foodborne diseases. Lack of hygiene was confirmed by presence of coliforms, S. aureus, and Enterococcus spp. The use of plastic covers, multipurpose sponges, and towels should be discouraged.
\end{abstract}

\section{Introduction}

Foodborne diseases remain a challenge globally, with higher incidence rate in developing countries. In 2010, the World Health Organization's Foodborne Disease Burden Epidemiology Reference Group estimated 582 million cases of foodborne diseases and 351000 associated deaths worldwide [1]. Furthermore, elderly people, children aged less than 5 years, pregnant women, and individuals with low immune systems could be more vulnerable to foodborne diseases [2]. Every year, contaminated food contributes to 1.5 billion cases of diarrhoea in children, resulting in more than three million premature deaths worldwide [3].

Foodborne diseases originating from home have been increasingly reported recently and now considered to be an important aspect of public health $[4,5]$. Households have been reported as the second most important venue for foodborne diseases after restaurants [6]. The incidence of home-based foodborne illnesses could be difficult to interpret due to various food sources and underreporting of illness $[4,6]$. A number of factors could contribute to foodborne diseases in the home, including types of food supply, domestic activities taking place in the kitchen, hygienic practices, attitudes, belief, experience, and knowledge of every member of the household $[4,7,8]$. Experimental studies have concluded that cross-contamination of bacteria which could cause foodborne illnesses such as S. aureus, Salmonella spp., and Campylobacter spp. could occur from fleshy food to raw foods, kitchen surfaces, and equipment, including chopping boards and knives $[4,9,10]$. It has also been reported that $50 \%$ of foodborne diseases were due to inappropriate food storage and $28 \%$ were due to cross-contamination [11]. Poor hygiene was found to significantly affect the presence of Escherichia coli 0157:H7 in homemade hamburgers [12].

Bacteria responsible for foodborne disease could cause biofilm on food contact surfaces such as tables which could disseminate the potential pathogens continuously in the kitchen environment as well as ultimately affecting food 
quality and safety [13]. The bacterial appendages, fimbriae, flagella and surface polysaccharides have been extensively studied for their contributions to the formation of biofilms by E. coli, Proteus spp., Pseudomonas spp., Klebsiella spp., and Salmonella spp. [13]. Proteus spp. have often been responsible for both food spoilage and food poisoning [14] whereas Pseudomonas spp., which are known to cause off-odours and off-flavours in food, have more often been cited as responsible for food deterioration and spoilage $[15,16]$.

In Mauritius, data from Ministry of Health and Quality of Health has indicated an ascending trend in the number of reported food poisoning cases, which was 2.0 cases in 2001 and increased to 31.0 cases per 100,000 midyear population in 2013. Furthermore, in 2013, diarrhoea and gastroenteritis of presumed infectious origin were the second cause of hospital discharge [17]. It would be impossible to estimate the percentage of home-based foodborne outbreaks, although it cannot be neglected. There is a need to study the sources and possible causes of foodborne diseases in household kitchens. Therefore, this study aimed to study the hygienic practices of a random sample of individuals in their home kitchens. The bacterial load and profile of potential pathogens and food spoilage bacteria from the home kitchen tables, dining and preparation tables, were investigated and compared. The various factors which might affect the load and presence of potential pathogens and food spoilage bacteria were also studied.

\section{Material and Methods}

2.1. Study Design. For the purpose of the study, a survey was initially carried out, followed by laboratory investigations. A questionnaire was designed which included four sections: firstly, general information of the family under study (age of members, family size/type, and diet); secondly, kitchen set-up (details of dining and preparation tables and their materials and cover and uses); thirdly, hygiene practices in the kitchen (hand washing frequency, use of chopping board); and, fourthly, food safety knowledge. The study was approved by the Department of Health Sciences, University of Mauritius.

2.2. Sample Collection. A total of 53 households provided the samples which were collected using sterile cotton swabs by swabbing over a $5 \mathrm{~cm} \times 5 \mathrm{~cm}$ surface area of kitchen tables. From each kitchen, four samples were obtained, one from dining table in the morning, one from dining table in the afternoon, one from preparation table in the morning, and one from preparation table in the afternoon. All the 212 samples were processed within 24 hours.

2.3. Laboratory Investigations. All kitchen samples were processed for a bacterial count which was read as colony forming units (CFU), followed by the isolation and identification of potential pathogens. A serial dilution was carried out from the original sample and spread plate technique was done to determine the $\mathrm{CFU} / 25 \mathrm{~cm}^{2}$. The samples were also streaked on sterile Nutrient Agar, MacConkey Agar, Bile
TABLE 1: Demographic details of families.

\begin{tabular}{lc}
\hline Details & $N(\%)$ \\
\hline Number of children & $17(32.1)$ \\
None & $27(50.9)$ \\
$1-2$ & $9(17.0)$ \\
$3-4$ & \\
Number of residents & $6(11.3)$ \\
$1-2$ & $22(41.5)$ \\
$3-4$ & $23(43.4)$ \\
$5-6$ & $2(3.8)$ \\
$7-8$ & \\
Number of adults & $16(30.2)$ \\
$1-2$ & $34(64.2)$ \\
$3-4$ & $3(5.7)$ \\
$>4$ & \\
Number of elders & $30(56.6)$ \\
None & $23(43.4)$ \\
1-2 & \\
Type of family & $4(7.5)$ \\
Couple only & $38(71.7)$ \\
Nuclear & $11(20.8)$ \\
Extended & \\
Diet of family & $8(15.1)$ \\
Vegetarian & $45(84.9)$ \\
Nonvegetarian &
\end{tabular}

Aesculin Agar, Salmonella Shigella Agar, Cetrimide Agar, and Sabouraud Agar (all from HiMedia, Mumbai, India). The potential pathogens were identified by conventional methods such as gram staining and biochemical tests such as catalase, coagulase, urease, oxidase, indole, methyl red, citrate, phenylpyruvic acid, and Kligler iron agar slant.

2.4. Statistical Analysis. Data analysis was done using SPSS v.19.0. Descriptive statistics were used to summarise demographic data. Independent sample $t$-test was used to calculate and compare between the bacterial load from the various sources. The odds ratio and difference in the prevalence of the potential pathogens were determined using Pearson's $\chi^{2}$ test. A $p$ value of less than 0.05 was read as significant. Odds ratio (OR) has been used to measure the association between potential pathogens and factors such as demographic details, types of table, usage of towels, and diet.

\section{Results}

3.1. Questionnaire. The demographic details of the families have been detailed on Table 1 .

The kitchen was busiest during dinner time (45.3\%) followed by morning breakfast (26.4\%), lunch (17.0\%), and afternoon tea time (11.3\%). Of the 53 dining tables, 44 were made of wood and 9 were made of plastic material. None of the plastic dining tables were covered while 37 (84.1\%) of the wood tables were covered with plastic cover with the rest 
TABLE 2: Prevalence of potential pathogens and food spoilage bacteria isolated from the tables.

\begin{tabular}{|c|c|c|c|c|c|c|c|}
\hline \multirow[b]{2}{*}{ Microorganism } & \multicolumn{7}{|c|}{ Prevalence of potential pathogen from tables } \\
\hline & $\begin{array}{c}\text { All } \\
(n=212) \\
\%\end{array}$ & $\begin{array}{c}\text { Dining } \\
(n=106) \\
\% \\
\end{array}$ & $\begin{array}{c}\text { Preparation } \\
(n=106) \\
\%\end{array}$ & $\begin{array}{c}\text { Dining AM } \\
(n=53) \\
\% \\
\end{array}$ & $\begin{array}{c}\text { Dining PM } \\
(n=53) \\
\% \\
\end{array}$ & $\begin{array}{c}\text { Preparation } \\
\operatorname{AM}(n=53) \\
\%\end{array}$ & $\begin{array}{c}\text { Preparation } \\
\operatorname{PM}(n=53) \\
\% \\
\end{array}$ \\
\hline S. aureus & 14.2 & 13.2 & 15.1 & 15.1 & 11.3 & 15.1 & 15.1 \\
\hline Enterococcus spp. & 34.9 & 33.0 & 36.8 & 30.2 & 35.8 & 45.3 & 28.3 \\
\hline Pseudomonas spp. & 10.4 & 5.7 & 15.1 & 3.8 & 7.5 & 15.1 & 15.1 \\
\hline Proteus spp. & 3.8 & 1.9 & 5.7 & 0 & 3.8 & 3.8 & 7.5 \\
\hline Coliforms $^{\#}$ & 23.1 & 17.9 & 28.3 & 18.9 & 17.0 & 28.3 & 28.3 \\
\hline
\end{tabular}

${ }^{\#}$ E. coli and Klebsiella spp. Dining AM: prevalence from samples collected in the morning from the dining tables. Dining PM: prevalence of potential pathogens from samples collected in the afternoon from the preparation tables.

TABLE 3: Factors affecting prevalence of coliforms.

\begin{tabular}{lc}
\hline Factors & Prevalence of coliforms \\
\hline Family type & $0 \%$ vs $20.4 \%: p<0.05:$ OR $=1.13(1.06-1.20)$ \\
$\quad$ Couple versus nuclear & $0 \%$ vs $40.9 \%: p<0.05:$ OR $=1.62(1.27-2.05)$ \\
Couple versus extended & $20.4 \%$ vs $40.9 \%: p<0.05:$ OR $=2.08(1.25-3.45)$ \\
$\quad$ Nuclear versus extended & $19.7 \%$ vs $0 \%: p<0.05:$ OR $=1.76(1.47-2.09)$ \\
Dining table: covered versus uncovered & $31.0 \%$ vs $0 \%: p<0.05:$ OR $=1.83(1.43-2.33)$ \\
Cover material of dining table: plastic versus cloth & $54.5 \%$ vs $24.7 \%: p<0.05:$ OR $=2.33(1.34-4.06)$ \\
Material of preparation table: wood versus ceramic & $65.0 \%$ vs $26.7 \%: p<0.05:$ OR $=3.61(1.58-8.25)$ \\
\hline
\end{tabular}

OR: odds ratio.

covered with cloth material. A total of 37 preparation tables were made of ceramics and 16 were made of wood material.

It was noted that $17(32.1 \%)$ households used their preparation tables as chopping boards and 27 (50.9\%) used the same chopping board for both vegetables and fleshy foods. Only $21(39.6 \%)$ of the respondents reported washing their hands always before preparing a meal or before eating. The frequency at which the kitchen was entirely cleaned was found to be daily for $18.9 \%$, weekly for $58.8 \%$, bimonthly for $17.0 \%$, and monthly for $5.7 \%$. For cleaning of the kitchen tables, $25(47.2 \%)$ used multipurpose sponges, $13(24.5 \%)$ used separate sponges, 13 (24.5\%) used multipurpose kitchen towels, and $2(3.8 \%)$ used separate kitchen towels. A high percentage of the respondents $(96.2 \%)$ reported that food safety was very important.

3.2. Laboratory Investigations. Out of the 212 samples, 168 (79.2\%) showed bacterial growth while yeast was noted in 27 (12.7\%). The mean CFU/25 $\mathrm{cm}^{2}$ from the kitchen tables per day was 3264, with a higher prevalence from the preparation tables compared to the dining tables (3433 versus 3095), although the difference was not significant. The time of collection was not found to affect the CFU significantly.

The material of the tables was found to affect bacterial load. Dining and preparation tables made of plastic had higher CFU compared to those made of wood ( $p<0.05)$. Furthermore, tables covered with plastic covers had higher CFU compared to cloth materials $(p<0.05)$. A significantly higher CFU/25 $\mathrm{cm}^{2}$ was noted from preparation tables which were also used as chopping boards (11185 versus 4839; $p<$ $0.05)$.
Good hand washing practice, that is, always washing hands before preparing meals or eating, was significantly associated with lower CFU from both dining and preparation tables $(p<0.05)$. The tables cleaned with multipurpose sponges had the highest load with $8475 \mathrm{CFU} / 25 \mathrm{~cm}^{2}$ followed by multipurpose kitchen towels which had $6049 \mathrm{CFU} / 25 \mathrm{~cm}^{2}$, with separate sponges $3670 \mathrm{CFU} / 25 \mathrm{~cm}^{2}$ and separate kitchen towels $826 \mathrm{CFU} / 25 \mathrm{~cm}^{2}$. The difference was statistically significant.

The potential pathogens isolated from the samples have been detailed in Table 2.

A higher prevalence of coliform was noted from preparation tables compared to dining tables (28.3\% versus $17.9 \%$; $p<$ $0.05 ; \mathrm{OR}=1.31(1.01-1.73))$, both in the morning $(28.3 \%$ versus $19.9 \% ; p<0.05:$ OR $=1.28(1.01-1.69))$ and in the afternoon (28.3\% versus $17.0 \% ; p<0.05$ : OR $=3.5(1.02-1.77))$. Pseudomonas spp. was also significantly more prevalent from the preparation table compared to dining tables ( $15.7 \%$ versus $5.1 \% ; p<0.05 ; \mathrm{OR}=1.53$ (1.14-2.6)). Among samples collected from the preparation tables, Enterococcus spp. was more prevalent in the morning samples ( $45.3 \%$ versus $28.3 \%$; $p<0.05 ; \mathrm{OR}=1.42(1.02-2.06))$.

A significant increase in the prevalence of coliform and Enterococcus spp. was found with increasing number of residents, children, adults, and elderly people $(p<0.05)$. It was also noted that more frequent cleaning of the kitchen and better hand hygiene, such as washing hands before preparing every meal or having meals, significantly decreased the prevalence of coliforms and Enterococcus spp. $(p<0.05)$. The other factors which significantly affected the presence of coliform have been detailed in Table 3 . 
TABLE 4: Effect of usage of towels on the detection rate of potential pathogens and food spoilage bacteria.

\begin{tabular}{|c|c|c|c|c|}
\hline \multirow[b]{2}{*}{ Prevalence of } & \multicolumn{3}{|c|}{ Cleaning materials of kitchen } & \multirow[b]{2}{*}{$\begin{array}{l}\text { Multipurpose sponge } \\
\text { versus multipurpose } \\
\text { towel }\end{array}$} \\
\hline & $\begin{array}{l}\text { Multipurpose sponge } \\
\text { versus separate sponge }\end{array}$ & $\begin{array}{l}\text { Multipurpose towel } \\
\text { versus separate towel }\end{array}$ & $\begin{array}{c}\text { Multipurpose towel } \\
\text { versus separate sponge }\end{array}$ & \\
\hline Coliforms $^{\#}$ & $\begin{array}{c}32.0 \% \text { vs } 0 \%: p<0.05: \\
\text { OR }=1.77(1.51-2.06)\end{array}$ & $\begin{array}{c}32.7 \% \text { vs } 0 \%: p<0.05: \\
\text { OR }=1.23(1.06-1.42)\end{array}$ & $\begin{array}{c}32.7 \% \text { vs } 0 \%: p<0.05: \\
\text { OR }=2.49(1.92-3.21)\end{array}$ & 32.0 vs $32.7 \%: p=\mathrm{NS}$ \\
\hline Enterococcus spp. & $\begin{array}{l}59.0 \% \text { vs } 0 \%: p<0.05: \\
\text { OR }=2.27(1.80-2.85)\end{array}$ & $\begin{array}{c}28.8 \% \text { vs } 0 \%: p<0.05: \\
\text { OR }=1.12(1.06-1.39)\end{array}$ & $\begin{array}{c}28.8 \% \text { vs } 0 \%: p<0.05: \\
\text { OR }=2.40(1.88-3.08)\end{array}$ & $\begin{array}{c}59.0 \% \text { vs } 28.8 \%: \\
p<0.05: \text { OR }=1.52 \\
\quad(1.19-1.93)\end{array}$ \\
\hline S. aureus & $11.5 \%$ vs $6.0 \%: p=\mathrm{NS}$ & $\begin{array}{c}50.0 \% \text { vs } 6.0 \%: p<0.05: \\
\text { OR }=9.8(2.88-33.32)\end{array}$ & $50.0 \%$ vs $6.0 \%: p=\mathrm{NS}$ & $11.5 \%$ vs $50.0 \%: p=\mathrm{NS}$ \\
\hline Pseudomonas spp. & $\begin{array}{c}6.0 \% \text { vs } 0 \%: p<0.05: \\
\text { OR }=1.55(1.38-1.75)\end{array}$ & $\begin{array}{c}30.8 \% \text { vs } 0 \%: p<0.05: \\
\text { OR }=1.22(1.06-1.40)\end{array}$ & $\begin{array}{c}30.8 \% \text { vs } 0 \%: p<0.05: \\
\mathrm{OR}=2.44(1.90-3.14)\end{array}$ & $\begin{array}{c}6.0 \% \text { vs } 30.8 \%: p<0.05 \\
\text { OR }=2.63(1.80-3.83)\end{array}$ \\
\hline Proteus spp. & $0 \%$ vs $0 \%: p=\mathrm{NS}$ & $15.4 \%$ vs $0 \%: p=\mathrm{NS}$ & $\begin{array}{c}15.4 \% \text { vs } 0 \%: p<0.05: \\
\text { OR }=2.18(1.75-2.71)\end{array}$ & $\begin{array}{l}0 \% \text { vs } 15.4 \%: p<0.05: \\
\text { OR }=3.27(2.56-4.19)\end{array}$ \\
\hline
\end{tabular}

${ }^{\#}$ E. coli and Klebsiella spp. NS: nonsignificant.

Enterococcus was also isolated at higher prevalence from households on nonvegetarian diets $(p<0.05)$ and from preparation tables which were also used as chopping boards (56.4\% versus $26.9 \%$ : $p<0.05:$ OR $=2.13(1.30-3.51)$ ).

$S$. aureus was more prevalent when the same chopping board was used for both vegetables and fleshy foods $(22.2 \%$ versus 5.8\%: $p<0.05: \mathrm{OR}=2.44(1.87-3.19))$. The association between potential pathogens and food spoilage bacteria from the kitchen tables and the cleaning materials used to clean the kitchens were also enquired (Table 4).

\section{Discussion}

It is now accepted that the prevalence of foodborne illnesses originating from home kitchens could not be neglected. However, most countries have not yet established adequate surveillance or reporting mechanisms to track home-based foodborne illnesses which could be due to technical and financial restraints.

In this study, it was found that although a very high percentage of respondents reported that food safety was a very important matter, only half of them used separate chopping board for vegetables and fleshy foods. Furthermore, only $39.6 \%$ adhered to good hand washing practice before handling food. It could be that either knowledge was not complete or knowledge was not always put into practice. Previous studies have also reported that knowledge and guidance in food safety do not always help in changing behavior [4].

The cleaning of the kitchens was done at different frequencies and more frequent cleaning was associated with lower prevalence of coliforms and Enterococcus spp. Food preparation and cleaning in the kitchen have been reported to be routine tasks [18] which could be mundane and taken for granted [19]. In a kitchen, the process of cleaning has been reported to vary from one household to another. Some people might clean to remove debris from the tables, some would tidy the surfaces, and very few would actually clean with the aim of removing microbes [4]. Therefore, microorganisms could very easily be transferred from one place to another.

The prevalence of E. coli and Enterococcus spp. was found to increase significantly in presence of elderly members and family size. It has been previously reported that food safety at home could be affected by the actions of every member using the kitchen [4]. Furthermore, the hands of older individuals were found to have a higher prevalence of coliforms compared to younger ones [7]. The elderly might be less strict about hygiene in the kitchen as they have been brought up in an era when processed food was consumed to lesser extent, refrigeration of foods was not in vogue, and the food supply chain was shorter [4].

In this study, $S$. aureus was the third most common potential pathogen isolated and was more prevalent when the same chopping board was used for both vegetables and fleshy foods. In an experimental study, S. aureus was found to have the highest rate of cross-contamination as compared to Campylobacter, Salmonella, and E. coli [10]. The presence of $S$. aureus on kitchen surfaces and food handlers hands has been associated with poor hygiene as the bacteria are highly susceptible to heat [7] and low concentrations of antibacterial dishwashing liquids [20].

As expected, a higher prevalence of potential pathogens was found from preparation tables compared to dining tables. The preparation tables are in contact with raw and fleshy foods more often. The presence of $S$. aureus and coliforms on kitchen counters and chopping boards has been previously reported. A significant increase of these potential pathogens was noted when the hands of the participants were positive to the same bacteria [7]. The use of preparation tables as chopping boards should be discouraged as this study found that such a practice significantly increased the CFU and prevalence of Enterococcus. One previous study reported an increase in prevalence of $S$. aureus and $E$. coli when preparation tables were used as chopping boards [7].

It was also revealed in this study that preparation tables made of wood have higher prevalence of coliform and Enterococcus spp. The nature of wood which is porous might 
allow penetration of juices from foods and bacteria, hence preventing their removal during cleaning and favouring their colonisation. Furthermore, plastic covers on both dining and preparation tables were associated with potential pathogens. The use of plastic covers on preparation tables should be discouraged as it was associated with high prevalence of coliforms. The cloth covers did not have coliform as the covers were most probably removed and washed as soon as they appear dirty whereas plastic covers might be wiped with sponges or towels to clean them for further use.

The hydrophobicity and roughness of surfaces together with the strain and surface physicochemical properties of the bacteria could affect initial adhesion process of foodborne bacteria to kitchen materials [9]. A review has concluded that strains of Listeria monocytogenes and Salmonella enteritidis could bind to various common surfaces in the kitchen including stainless steel, polypropylene, cutting board, and silestone, but with different degree of adhesion [9]. E. coli and $S$. aureus survived on polyethylene materials for longer period of time [21]. The irregular surfaces of plastic material could favour the accumulation of organic matter and food residues, which could increase the attachment and survival of bacteria [22].

Several studies have concluded that kitchen cloths and sponges become contaminated during use and could be important in cross-contaminating kitchen utensils and surfaces $[23,24]$. This study did not isolate bacteria directly from sponges. However, a higher mean CFU and potential pathogens were noted from kitchen tables which were cleaned with multipurpose sponges and towels compared to separate ones. Studies have concluded that $S$. aureus and other foodborne illness causing bacteria could be transmitted from contaminated sponges to kitchen surfaces [24]. Furthermore, it was reported that washing of sponges contaminated with food did not reduce the bacterial load significantly [20]. Therefore, the use of multipurpose sponges and towels should be avoided in kitchens.

The association of coliforms and S. aureus with foodborne diseases has been well documented. Enterococcus have also been recently studied as potential indicators of faecal contamination on hands as they are present in large numbers in human faeces and persist in the environment [25]. In the United Kingdom, enterococci are regarded as secondary indicators of faecal pollution [26]. The World Health Organization has recommended the adoption of enterococci as an indicator of recreational water quality [25, 27]. Faecal enterococci from human beings have been reported to be avirulent [25]. However, their presence on kitchen tables, towels, and sponges would indicate lack of hygiene which could eventually affect food safety.

\section{Conclusion}

The present study revealed that kitchen tables at home could be very important sources of potential pathogens which have been reported to cause foodborne illnesses. The use of plastic covers on kitchen tables, multipurpose sponges, and towels should be discouraged in the kitchen. Lack of hygiene was confirmed by presence of coliforms, S. aureus, and Enterococcus spp. on the tables. Furthermore, people should be encouraged to apply basic food hygiene practices at home to ensure food safety.

\section{Competing Interests}

The authors declare that they have no conflict of interests.

\section{Authors' Contributions}

Susheela Biranjia-Hurdoyal supervised the study. Melissa Cathleen Latouche carried out the experimental work and preliminary data analysis and partly drafted the paper. Susheela Biranjia-Hurdoyal finalised the data analysis and paper. Both authors read and approved the final paper.

\section{Acknowledgments}

The authors are grateful to all the volunteers. The University of Mauritius funded the practical component of this project.

\section{References}

[1] World Health Organization, 2015, http://www.who.int/mediacentre/news/releases/2015/food-safety/en/.

[2] E. C. Redmond and C. J. Griffith, "Assessment of consumer food safety education provided by local authorities in the UK," British Food Journal, vol. 108, no. 9, pp. 732-752, 2006.

[3] World Health Organization, "WHO estimates of the global burden of foodborne diseases. Foodborne disease Burden epidemiology Reference group 2007-2015," 2015, http://apps.who.int/ iris/bitstream/10665/199350/1/9789241565165_eng.pdf.

[4] W. J. Wills, A. Meah, A. M. Dickinson, and F. Short, "I don't think I ever had food poisoning. A practice-based approach to understanding foodborne disease that originates in the home," Appetite, vol. 85, pp. 118-125, 2015.

[5] E. Scott, "Food safety and foodborne disease in 21st century homes," Canadian Journal of Infectious Diseases, vol. 14, no. 5, pp. 277-280, 2003.

[6] M. Lynch, J. Painter, R. Woodruff, and C. Braden, "Surveillance for foodborne-disease outbreaks-United States, 19982002," Morbidity and Mortality Weekly Report. Surveillance Summaries, vol. 55, no. 10, pp. 1-42, 2006.

[7] J. M. Dharod, S. Paciello, A. Bermúdez-Millán, K. Venkitanarayanan, G. Damio, and R. Pérez-Escamilla, "Bacterial contamination of hands increases risk of cross-contamination among low-income Puerto Rican meal preparers," Journal of Nutrition Education and Behavior, vol. 41, no. 6, pp. 389-397, 2009.

[8] S. R. Patil, S. Cates, and R. Morales, "Consumer food safety knowledge, practices, and demographic differences: findings from a meta-analysis," Journal of Food Protection, vol. 68, no. 9, pp. 1884-1894, 2005.

[9] P. Teixeira, S. Silva, F. Araújo, J. Azeredo, and R. Oliveira, "Bacterial Adhesion to food contacting surfaces," in Communicating Current Research and Education Topics and Trends in Applied Microbiology, A. Mendez-Vilas, Ed., vol. 1 of Microbiology, 2007.

[10] R. Gorman, S. Bloomfield, and C. C. Adley, "A study of crosscontamination of food-borne pathogens in the domestic 
kitchen in the Republic of Ireland," International Journal of Food Microbiology, vol. 76, no. 1-2, pp. 143-150, 2002.

[11] H. S. Evans, P. Madde, and C. Douglas, "General outbreaks of infectious intestinal disease in England and Wales: 1995 and 1996," Communicable Disease and Public Health, vol. 1, no. 3, pp. 167-171, 1995.

[12] P. A. Mead, L. Finclli, M. A. Lambert-Fair et al., "Risk factors for sporadic infection with Escherichia coli O157:H7," Archives of Internal Medicine, vol. 157, no. 2, pp. 204-208, 1997.

[13] R. Van Houdt and C. W. Michiels, "Biofilm formation and the food industry, a focus on the bacterial outer surface," Journal of Applied Microbiology, vol. 109, no. 4, pp. 1117-1131, 2010.

[14] Y. Wang, S. Zhang, J. Yu et al., "An outbreak of Proteus mirabilis food poisoning associated with eating stewed pork balls in brown sauce, Beijing," Food Control, vol. 21, no. 3, pp. 302-305, 2010.

[15] L. Pinto, A. Ippolito, and F. Baruzzi, "Control of spoiler Pseudomonas spp. on fresh cut vegetables by neutral electrolyzed water," Food Microbiology, vol. 50, pp. 102-108, 2015.

[16] H. Mith, R. Duré, V. Delcenserie, A. Zhiri, G. Daube, and A. Clinquart, "Antimicrobial activities of commercial essential oils and their components against food-borne pathogens and food spoilage bacteria," Food Science \& Nutrition, vol. 2, no. 4, pp. 403-416, 2014.

[17] Republic of Mauritius, Ministry of Health and Quality of Life (MIH), Health statistics report 2013, http://health.govmu.org.

[18] A. R. H. Fischer, L. J. Frewer, and M. J. Nauta, "Toward improving food safety in the domestic environment: a multiitem rasch scale for the measurement of the safety efficacy of domestic food-handling practices," Risk Analysis, vol. 26, no. 5, pp. 1323-1338, 2006.

[19] E. M. Power, "De-centering the text: exploring the potential for visual methods in the sociology of food," Journal for the Study of Food and Society, vol. 6, no. 2, pp. 9-20, 2003.

[20] H. D. Kusumaningrum, M. M. van Putten, F. M. Rombouts, and R. R. Beumer, "Effects of antibacterial dishwashing liquid on foodborne pathogens and competitive microorganisms in kitchen sponges," Journal of Food Protection, vol. 65, no. 1, pp. 61-65, 2002.

[21] E. M. Rossi, D. Scapin, and E. C. Tondo, "Survival and transfer of microorganisms from kitchen sponges to surfaces of stainless steel and polyethylene," Journal of Infection in Developing Countries, vol. 7, no. 3, pp. 229-234, 2013.

[22] E. Sinde and J. Carballo, "Attachment of Salmonella spp. and Listeria monocytogenes to stainless steel, rubber and polytetrafluorethylene: the influence of free energy and the effect of commercial sanitizers," Food Microbiology, vol. 17, no. 4, pp. 439-447, 2000.

[23] K. Mattick, K. Durham, G. Domingue et al., "The survival of foodborne pathogens during domestic washing-up and subsequent transfer onto washing-up sponges, kitchen surfaces and food," International Journal of Food Microbiology, vol. 85, no. 3, pp. 213-226, 2003.

[24] H. D. Kusumaningrum, G. Riboldi, W. C. Hazeleger, and R. R. Beumer, "Survival of foodborne pathogens on stainless steel surfaces and cross-contamination to foods," International Journal of Food Microbiology, vol. 85, no. 3, pp. 227-236, 2003.

[25] A. B. Boehm and A. M. Sassoubre, Enterococci as Indicators of Environmental Fecal Contamination, 2014.

[26] Environment Agency, The Microbiology of Drinking WaterPart 5-Methods for the Isolation and enumeration of enterococci, 2012, https://www.gov.uk/government/uploads/ system/uploads/attachment_data/file/316734/geho0812bwwj-ee.pdf.

[27] World Health Organization, "Water Sanitation health. Guidelines for safe recreational water environments Volume 1: Coastal and fresh waters," 2015, http://www.who.int/water sanitation_health/bathing. 


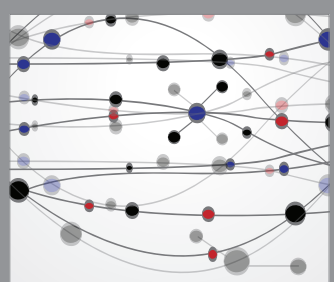

The Scientific World Journal
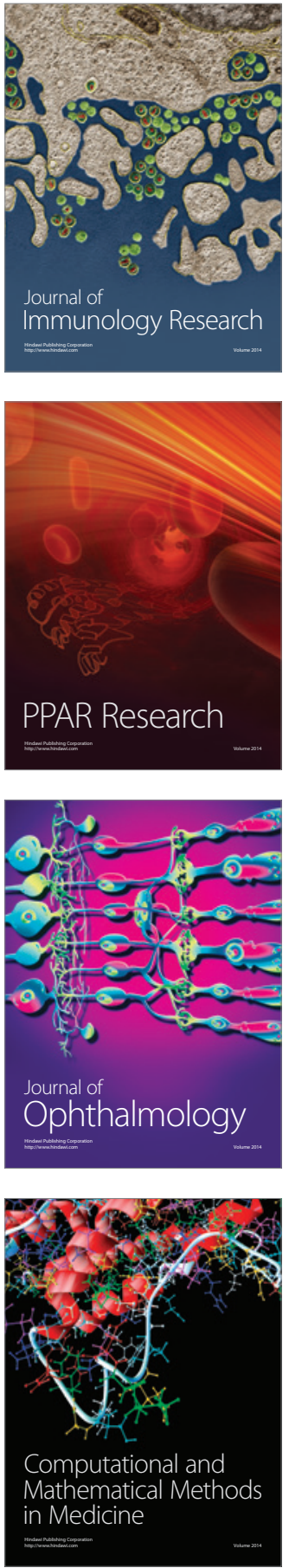

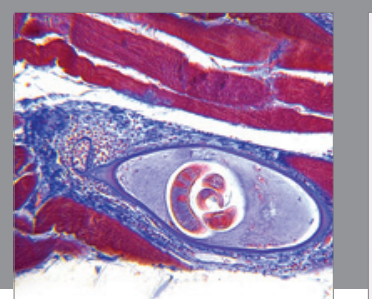

Gastroenterology Research and Practice

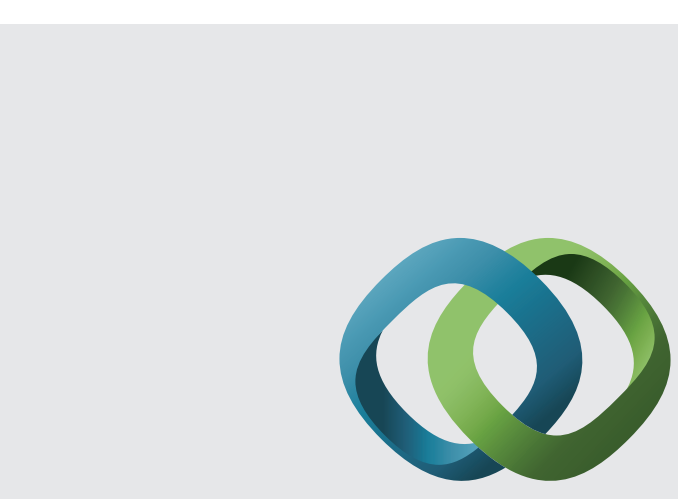

\section{Hindawi}

Submit your manuscripts at

http://www.hindawi.com
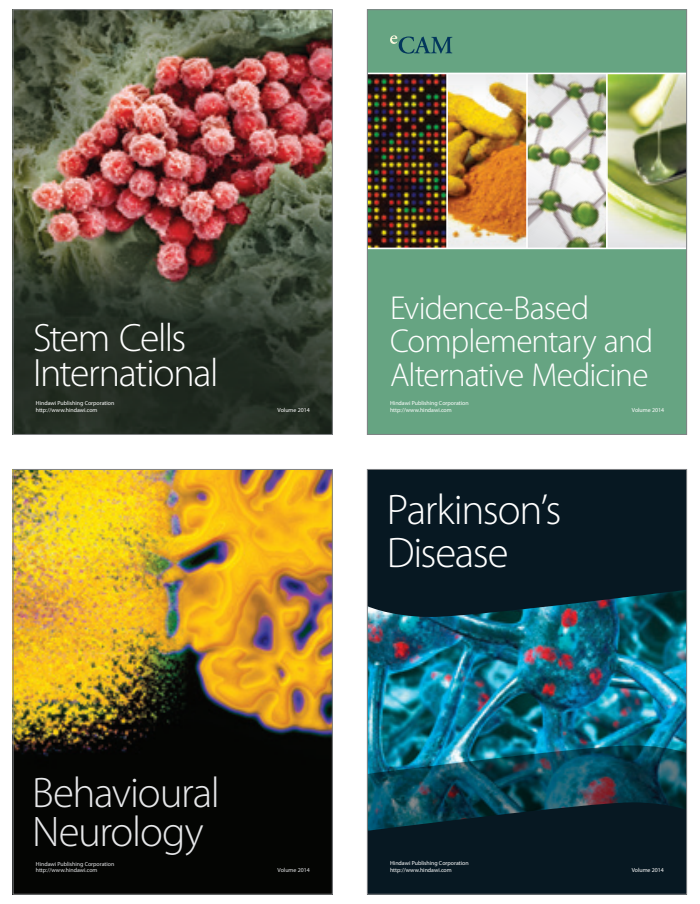
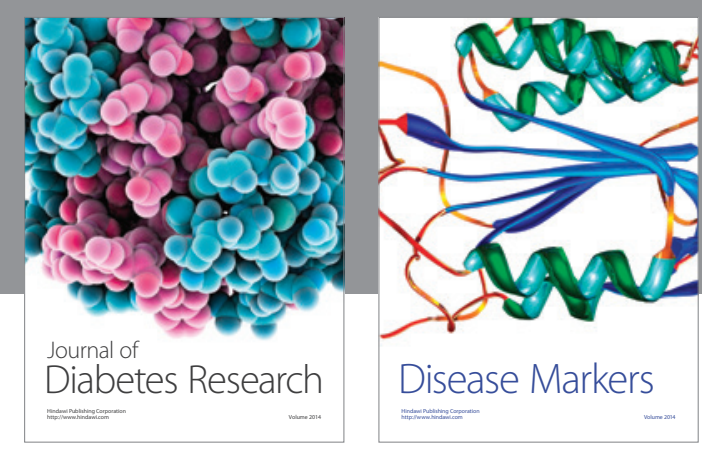

Disease Markers
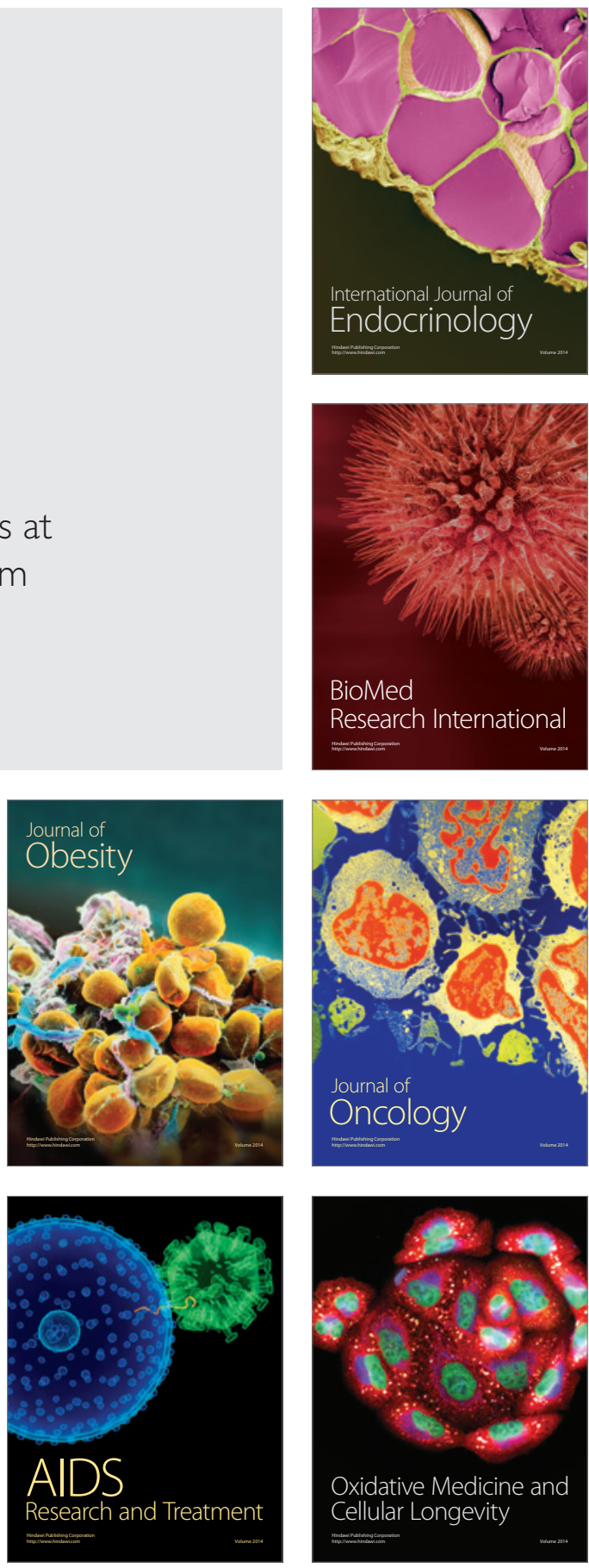